\title{
Low frequency dielectric spectroscopy of bitumen binders as an indicator of adhesion potential to quartz aggregates using Portland cement
}

\author{
AUTHORS: Åsa Laurell Lyne* - Nathaniel Taylor** - Nadja Jaeverberg ** - Hans \\ Edin** - and Björn Birgisson*,*** \\ * Highway and Railway Engineering, School of Architecture and the Built Environment, KTH \\ Royal Institute of Technology, SE-100 44 Stockholm, Sweden \\ ** Electromagnetic Engineering, School of Electrical Engineering, KTH Royal Institute of \\ Technology, SE-100 44 Stockholm, Sweden \\ ***Aston University, School of Engineering and Applied Science, Aston Circle, Birmingham, \\ B4 $7 E T$
}

Corresponding author: Åsa Laurell Lyne alll@kth.se +46705095544

\section{ABSTRACT}

The purpose of this investigation was to interpret the bitumen-aggregate adhesion based on the dielectric spectroscopic response of individual material components utilizing their dielectric constants, refractive indices and average tangent of the dielectric loss angle (average loss tangent). Dielectric spectroscopy of bitumen binders at room temperature was performed in the frequency range of 0.01 to 1000 $\mathrm{Hz}$. Dielectric spectroscopy is an experimental method for characterizing the dielectric permittivity of a material as a function of frequency. Adhesion data has been determined using the Rolling bottle method.

The results show that the magnitude of the average tangent of the dielectric loss angle (average loss tangent) depends on bitumen type. The average loss tangent in the frequency range 0.01 to $1 \mathrm{~Hz}$ is introduced as a potential indicator for predicting polarizability and, thereby, adhesion potential of bitumen binders to quartz aggregates when using Portland cement. In order to obtain acceptable adhesion of 70/100 penetration grade bitumen binders and quartz aggregates when using Portland cement, it is suggested that the binder have an average $\tan \delta>0.035$ in the frequency range 0.01 to $1 \mathrm{~Hz}$.

Keywords: bitumen, quartz, Portland cement, dielectric constant, permittivity, average loss tangent, polarizability. 


\section{INTRODUCTION}

Impairment of the integrity of asphalt due to detachment of bitumen from mineral aggregates in the presence of water has been an issue ever since the beginning of asphalt composite pavements. Water can decrease the bitumen/filler (mastic) interaction, and the cohesive bitumen/bitumen interaction.

Bitumen is a sticky material used as a binder material and is mixed with aggregate particles to form asphalt pavement. The bitumen binder can be seen as the matrix material that surrounds the aggregate particles, and the function of the bitumen binder is to adhere the aggregate particles together with sufficient strength that the asphalt composite is capable of supporting the high stresses caused by traffic. Adhesive properties of bitumen and aggregates vary with their inherently complex compositions.

Bitumen consists of a heterogeneous blend of hydrocarbons, with limited amounts of sulfur, oxygen, and nitrogen, and trace amounts of vanadium, nickel and iron incorporated into the molecular structures. In the literature, "asphaltenes" refers to very heterogeneous compounds, defined as a bitumen fraction insoluble in $\mathrm{n}$ heptane. In this paper asphaltenes will be referred to as the $n$ - heptane insoluble fraction.

The aggregate surface is typically non-uniform corresponding to mineral composition and configuration. A mineral is a naturally occurring solid chemical substance with an orderly repeating pattern, usually with a highly ordered atomic structure.

Dielectric spectroscopy is an experimental technique used to characterize molecular structures and their mobility in an electric field as a function of frequency or as a function of time. Permittivity is a measure of the extent to which an electric field influences, and is influenced by the charges in a dielectric material. The main objective in studying permittivity is to relate macroscopic properties such as the dielectric constant to microscopic properties such as the molecular polarizability. With no material present, the free-space relative permittivity (dielectric constant) is 1 , by definition. Addition of material introduces an increased permittivity due to electronic polarization and London dispersive polarizability; at zero frequency the Keesom and Debye attraction energies will be responsible for a significant part of the polarization in materials with higher permittivity. 
The present paper is aimed at investigating adhesion properties of virgin (i.e. unaged) 70/100 penetration grade bitumen binders by means of permittivity analysis, specifically by:

- identifying a cut-off point in dielectric constant for materials and solvents, above which they can be considered polarizable / polar,

- determine dielectric the spectroscopic response at low frequencies,

- introducing tangent of the dielectric loss angle as a potential indicator for predicting polarizability and thereby the adhesion potential of bitumen binders.

- using Portland cement to enhance bitumen-aggregate adhesion .

\section{THEORY}

\section{Permittivity}

Permittivity as a function of frequency has real, $\varepsilon_{r}^{\prime}$, and imaginary, $\varepsilon_{r}^{\prime \prime}$, values,

$$
\begin{gathered}
\varepsilon^{\prime}{ }_{r}=\frac{\mathrm{d} \cdot \mathrm{C}_{P}}{\varepsilon_{0} \cdot \mathrm{A}} \\
\varepsilon^{\prime \prime}{ }_{r}=\frac{\mathrm{d} \cdot \mathrm{C}_{S}}{\varepsilon_{0} \cdot \mathrm{A}}
\end{gathered}
$$

where $C_{p}$ and $C_{s}$ are the real and imaginary parts of complex capacitance measured by the instrument, and vacuum permittivity, $\varepsilon_{0}$, is $\sim 8.85 \times 10^{-12} \mathrm{~F} / \mathrm{m}$.

The real part of the permittivity may also be referred to as the dielectric constant.

The relative complex permittivity, $\varepsilon_{r}$, of a material is defined as:

$$
\varepsilon_{r}=\varepsilon^{\prime}{ }_{r}-j \varepsilon^{\prime \prime}{ }_{r}
$$

The tangent of loss angle (or loss tangent) is defined as:

$$
\text { tangent } \delta=\frac{\varepsilon \prime^{\prime \prime}}{\varepsilon \prime_{r}}=\frac{\mathrm{C}_{S}}{\mathrm{C}_{P}}
$$

Under a sinusoidal field, the current density can be written as [1]:

$$
J(\omega)=E(\omega) i \varepsilon_{r} \omega\left[1+\chi^{\prime}(\omega)-i\left(\frac{\sigma}{\varepsilon_{0} \omega}+\chi^{\prime \prime}(\omega)\right)\right]
$$

where $\omega$ is the angular frequency, $\sigma$ is the DC conductivity, and $\chi$ and $\chi^{\prime \prime}$ are the real and imaginary components of the complex susceptibility.

The real component of $\varepsilon_{r}$ is:

$$
\varepsilon^{\prime}{ }_{r}=1+\chi^{\prime}(\omega)
$$


The imaginary component of $\varepsilon_{r}$ is:

$$
\varepsilon^{\prime \prime} r=\frac{\sigma}{\varepsilon_{0} \omega}+\chi^{\prime \prime}(\omega)
$$

At low frequencies, the conductivity adds further to $\varepsilon^{\prime \prime}{ }_{r}$ [1]. DC conductivity may provide a gradient of -1 in the regular log-log graphs of $\varepsilon^{\prime \prime} r$.

$\varepsilon^{\prime}{ }_{r}$ may be largely frequency-independent in some frequency ranges, but can also have a gradient approaching -1 at low frequencies. When both $\varepsilon^{\prime}{ }_{r}$ and $\varepsilon^{\prime \prime}{ }_{r}$ increase towards low frequencies, this is referred to as 'low frequency dispersion' [2].

\section{Polarizability}

Polarizability is the potential of a molecule or substance to become polarized in an electric field. Non-polar molecules have symmetric arrangements of electrons in their electron clouds. The electron clouds can be distorted in the presence of an electric field, and the degree to which this occurs is defined as the London dispersive (electronic) polarizability of the molecule, $\alpha_{0}$. All molecules have a London dispersive (electronic) polarizability. Some molecules have asymmetric arrangements making them polar, i.e. they will exhibit a permanent dipole moment.

According to the Clausius-Mossotti equation, the total polarizability, $\alpha$, is related to the chemical structure of the material through the dielectric constant, $\varepsilon_{r}$ :

$$
\frac{\alpha}{\left(4 \pi \varepsilon_{0}\right)}=\left(\frac{\varepsilon_{r}-1}{\varepsilon_{r}+2}\right) \frac{3 v}{4 \pi}
$$

According to the Lorenz-Lorentz equation, the London dispersive (electronic) polarizability, $\alpha_{0}$, is related to the chemical structure of the material through refractive index, $n$ :

$$
\frac{\alpha_{0}}{\left(4 \pi \varepsilon_{0}\right)}=\left(\frac{n^{2}-1}{n^{2}+2}\right) \frac{3 v}{4 \pi}
$$

where $v=\frac{M}{\rho N_{0}}, M$ is the molecular weight, $\rho$ is the mass density, and $N_{0}$ is Avogadro's number.

\section{Keesom dipole-dipole interaction}

The energy of interaction between two rotating dipoles may be expressed as the Keesom or orientation interaction:

$$
w(r)=-\frac{u_{1}^{2} u_{2}^{2}}{3\left(4 \pi \varepsilon_{0} \varepsilon_{r}\right)^{2} k T r^{6}}
$$

where $u$ is the dipole moment, $\varepsilon_{0}$ is the permittivity of free space, $\varepsilon_{r}$ is the dielectric constant of surrounding material, and $r$ is distance between molecules, $k$ is Boltzmann's constant and $T$ is absolute temperature. 


\section{Debye dipole-induced dipole interaction}

The energy of interaction the between a rotating dipole and an induced dipole may be expressed as the Debye dipole-induced dipole interaction:

$$
w(r)=-\frac{u_{1}^{2} \alpha_{02}+u_{2}^{2} \alpha_{01}}{\left(4 \pi \varepsilon_{0} \varepsilon_{r}\right)^{2} r^{6}}
$$

\section{Non-polar London induced dipole-induced dipole interaction}

The energy of interaction between two different molecules with induced dipoleinduced dipole, may be expressed as the non-polar London induced dipole-induced dipole interaction:

$$
w(r)=-\frac{3}{2} \frac{\alpha_{01} \alpha_{02}}{\left(4 \pi \varepsilon_{0} \varepsilon_{r}\right)^{2} r^{6}} \frac{h v_{1} v_{2}}{\left(v_{1}+v_{2}\right)}
$$

where $h$ is Planck's constant and $v$ is the molar volume.

\section{MATERIAL AND METHODS}

Material. Seven 70/100 penetration grade bitumen binders according to EN 12591:2009 were included in this study.

Preparation of samples. In order to get the binder to flow out of the container the binder was heated to $150{ }^{\circ} \mathrm{C}$ for approximately 30 minutes. The binder was thoroughly stirred and then poured into $1 \mathrm{~cm}$ deep stainless steel sample holders.

Permittivity measurements. An IDAX-300 Insulation Diagnostic Analyzer from Megger was used to measure dielectric permittivity. It is a low frequency impedance analyzer and was used in the frequency range from $10^{-2}$ to $10^{4} \mathrm{~Hz}$. The total area of the electrode on which the current was measured was $41.8 \mathrm{~cm}^{2}$ and the distance between the electrodes was $1 \mathrm{~cm}$.

Permittivity is calculated from capacitance measurements using the parallel plate method. The two electrodes consisted of the stainless steel cup containing the bitumen sample and a brass plate placed on top of the bitumen sample. A guard electrode (also made of brass) was used outside the brass plate electrode in order to minimize measurement errors caused by edge capacitance. The gap between the guard and central electrode was $2 \mathrm{~mm}$.

Surface Coverage (early adhesion). The rolling bottle method was used according to SS-EN 12697-11. The amount of bitumen remaining on aggregates is visually determined after mechanical stirring of bitumen-covered aggregates in water. The 
samples were photographed after 24 hours agitation in water and the percentage bitumen adhering to quartz aggregates determined. 


\section{RESULTS AND DISCUSSION}

\subsection{Identifying cut-off point in dielectric constant}

Non-polar and polar interactions. Materials may be classified as non-polar or polar. Non-polar functional groups in bitumen are associated with hydrocarbons that contain only carbon and hydrogen. Alkanes and cycloalkanes are examples of these functional groups.

Polar molecules contain elements that cause an electronegativity difference between them and hydrogen and carbon. In bitumen, naturally occurring heteroatoms like nitrogen, oxygen, and sulfur, may contribute to polarity. A dipole can induce an otherwise non-polar material by proximity. All atoms and molecules are polarizable.

Materials with only non-polar functional groups have low dielectric constants and materials containing polar functional groups have higher dielectric constants.

By cut-off point we mean value of dielectric constant above which materials can be considered polarizable / polar since they contain polar functional groups.

Solvents and polymeric materials with low and high molecular weights. The dielectric constant of low molecular weight solvents and high molecular weight polymeric materials are summarized in Tables $\mathbf{1}$ and $\mathbf{2}$. The dielectric constant is defined in the $10^{6}$ to $10^{9}$ frequency range. Note that the solvents and materials presented in Tables 1 and $\mathbf{2}$ do not exist in bitumen. Non-polar functional groups in bitumen are associated with hydrocarbon groups that contain only carbon and hydrogen. It can be observed in Tables 1 and $\mathbf{2}$ that the dielectric constant of materials and solvents with only non-polar functional groups is below approximately 3 indicating a low degree of total polarizability.

The dielectric constant of materials and solvents containing functional groups with oxygen and nitrogen is above approximately 3 indicating their higher degree of total polarizability.

As seen in Tables 1 and 2, the dielectric constant is a measure of degree of electronegativity, indicated by type of polar functional group. Solvents with much smaller molecular weights in Table 1 have dielectric constants in the same range as the materials in Table 2 that have much higher molecular weights.

Solvents and polymeric materials containing molecules with very different electronegativities also interact through hydrogen bonding and polar bonding. These solvents and materials have in general high dielectric constants and do not exist in non-aged bitumen. Alcohols, acids and water are examples of solvents with high dielectric constants. 
Table1 Dielectric constant of (low molecular weight) solvents.

\begin{tabular}{|l|l|l|l|}
\hline Solvent & Functional groups & $\varepsilon$ & Ref. \\
\hline n-heptane & Straight chain alkane & 1.9 & {$[8]$} \\
\hline Ethyl benzene & Functionalized arene with ethyl group & 2.3 & {$[9]$} \\
\hline 0-Xylene & $\begin{array}{l}\text { Functionalized arene with alkyl } \\
\text { groups }\end{array}$ & 2.3 & {$[10]$} \\
\hline Toluene & Functionalized arene with alkyl group & 2.4 & {$[8]$} \\
\hline Hexyl acetate & Functionalized ester with alkyl group & 4.4 & {$[11]$} \\
\hline Cyclohexyl-amine & $\begin{array}{l}\text { Functionalized cyclohexane with } \\
\text { aliphatic amine group }\end{array}$ & 4.6 & {$[12]$} \\
\hline Methyl benzoate & Functionalized arene with ester group & 6.6 & {$[13]$} \\
\hline Tetrahydro-furan & $\begin{array}{l}\text { Functionalized cyclopentane with } \\
\text { ether group }\end{array}$ & 7.6 & {$[14]$} \\
\hline Benzophenone & $\begin{array}{l}\text { Functionalized arenes with a ketone } \\
\text { in between }\end{array}$ & 13 & {$[15]$} \\
\hline Cyclohexanone & $\begin{array}{l}\text { Functionalized cyclohexane with } \\
\text { ketone }\end{array}$ & 18.3 & {$[16]$} \\
\hline
\end{tabular}

Table 2 Dielectric constant of polymeric (high molecular weight) materials.

\begin{tabular}{|c|c|c|c|c|}
\hline Material & Repeating unit & $\begin{array}{l}\text { Molecular } \\
\text { formula }\end{array}$ & $\varepsilon$ & Ref. \\
\hline Polyethylene & & $\left(\mathrm{C}_{2} \mathrm{H}_{4}\right)_{\mathrm{n}} \mathrm{H}_{2}$. & 2.3 & $\begin{array}{l}\text { [Lanza and } \\
\text { Herrmann } \\
17]\end{array}$ \\
\hline Polypropylene & & $\left(\mathrm{C}_{3} \mathrm{H}_{6}\right) \mathrm{n}$ & 2.2 & $\begin{array}{l}\text { [Anderson } \\
\text { and McCall } \\
18]\end{array}$ \\
\hline Polystyrene & & $\left(\mathrm{C}_{8} \mathrm{H}_{8}\right)_{\mathrm{n}}$ & $2.4-3.0$ & [19] \\
\hline Polycarbonate & & & 2.8 & $\begin{array}{l}\text { [Rabuffi and } \\
\text { Picci 20] }\end{array}$ \\
\hline Polyphenylenesulfide & & & 3.0 & $\begin{array}{l}\text { [Rabuffi and } \\
\text { Picci 20] }\end{array}$ \\
\hline Polyester & & & 3.3 & $\begin{array}{l}\text { [Rabuffi and } \\
\text { Picci 20] }\end{array}$ \\
\hline $\begin{array}{l}\text { Poly (n-nutyl } \\
\text { methacrylate) }\end{array}$ & & & 4.28 & $\begin{array}{l}\text { [Havriliak } \\
\text { and Negami } \\
\text { 21] }\end{array}$ \\
\hline Polyacrylate & & $\left(\mathrm{CH}_{2}=\mathrm{CHCO}_{2} \mathrm{R}\right)$ & 6.5 & $\begin{array}{l}\text { [Havriliak } \\
\text { and Negami } \\
\text { 21] }\end{array}$ \\
\hline
\end{tabular}




\subsection{Polarizability of bitumen}

Total polarizability. In this study, the dielectric constant at $1000 \mathrm{~Hz}$ was determined for bitumen binders $\boldsymbol{a}$ to $\boldsymbol{g}$ and varied between ${\varepsilon^{\prime}}_{r}=3.2$ to 3.9 (and $\varepsilon_{r}=3.1$ to 3.8). A dielectric constant of 3.1 to 3.8 indicates that bitumen as a whole consists mainly of molecules with non-polar functional groups and that the total polarizability (see Equation 8) at zero frequency therefore is low.

There exists a small fraction of $n$-heptane insoluble molecules (i.e. asphaltenes) in bitumen. The dielectric constant of 5-7 for asphaltenes indicate that these molecules have a somewhat higher total polarizability than bitumen as a whole [22]. Dipole moments up to 7.7 (in Debye) have been reported for asphaltenes by Goual and Firoozabadi [23]. In materials with higher permittivity at zero frequency the Keesom and Debye attraction energies will be responsible for a significant part of the polarization.

London dispersive polarizability. Ellipsometry has recently been used to determine the refractive index of bitumen [24] that was in the range 1.55 to 1.60 . The refractive index of the $n$-heptane insoluble fraction has been reported to 1.682 [22]. It has been concluded that non-aged bitumen as a whole is highly London dispersive (electronic) polarizable (see Equation 9) and that the asphaltene (or n-heptane insoluble) fraction is even higher London dispersive (electronic) polarizable. The degree of non-polar London dispersion polarizability increases with increasing molecular size and with increasing aromaticity.

\subsection{Polarizability of quartz and Portland cement}

As seen in Table 3, quartz (i.e. $\mathrm{SiO}_{2}$ ) has a 'low' refractive index of 1.55 and a 'low' dielectric constant of 4.2 . From these values it can be concluded that pure silica has a lower London dispersive polarization (in comparison with other minerals) and a low total polarization. The interaction between silica and bitumen can therefore be considered primarily London dispersive.

A typical Portland cement contains 63 percent calcium oxide, 1.5 percent magnesium oxide and 3 percent iron oxide [25]. MgO has a high refractive index of 1.74 and a high dielectric constant of 9.90, $\mathrm{CaO}$ has a high refractive index of 1.84 and a high dielectric constant of 11.95, and iron oxides have even higher refractive indices of 2.11-2.73 (depending on iron oxide type) and an even higher dielectric constants of 20.6-31.4 (also depending on iron oxide type) [26].

$\mathrm{MgO}, \mathrm{CaO}$ and iron oxides all have high refractive indices indicating their high degree of London dispersive polarizability. All oxides have also high dielectric constants, 
especially iron oxides, indicating their high degree of total polarizability. Portland cement is a material strongly contributing to Debye and Keesom interactions.

The dielectric constant of iron oxides is as high as some polar compounds and solvents such as acetone (20.7) and ethanol (24.3). The reactivity of iron oxides may also add to bonding to aggregates.

Table 3 Refractive indices and dielectric constants of oxides.

\begin{tabular}{|l|l|l|}
\hline Oxides & $\begin{array}{l}\text { Refractive Index } \\
{[27]}\end{array}$ & Dielectric Constant \\
\hline $\mathrm{SiO}_{2}$ (silica) & $\begin{array}{l}\mathrm{w}=1.543-1.545 \\
\mathrm{e}=1.552-1.554\end{array}$ & $4.2[28]$ \\
\hline $\mathrm{MgO}$ & 1.74 & $9.90[29]$ \\
\hline $\mathrm{CaO}$ & 1.84 & $11.95[29]$ \\
\hline $\begin{array}{l}\text {-Iron II oxide }(\mathrm{FeO}) \\
\text {-Iron III oxide }\left(\mathrm{Fe}_{2} \mathrm{O}_{3}\right) \\
\begin{array}{l}\text { also known as hematite, } \\
\text { occurs in the mineral } \\
\text { magnetite. }\end{array}\end{array}$ & $\begin{array}{l}2.11,2.13(\mathrm{FeO}) \\
\mathrm{w}=24, \mathrm{e}=31.4(\mathrm{FeO})[30] \\
\mathrm{w}=20.6, \mathrm{e}=24.1\left(\mathrm{Fe}_{2} \mathrm{O}_{3}\right) \\
{[30]}\end{array}$ \\
\hline
\end{tabular}

\subsection{The complex relative permittivity}

The frequency dependence of the real part and the imaginary part of the complex relative permittivity of seven bitumen binders was investigated over the frequency range $10^{-2}$ to $10^{3} \mathrm{~Hz}$ (as illustrated in Figures 1 and 2).

As the frequency is decreased, the real part of the complex permittivity increases slightly in the entire frequency range for all bitumen binders, whereas the imaginary part of the complex permittivity increases slightly down to below $1 \mathrm{~Hz}$ and thereafter increases faster and shows a broader differentiation among the bitumen samples. The measurements were performed on bitumen binders at room temperature where bitumen behaves like a highly viscous liquid. 




Figure 1 Real Part of the Complex Relative Permittivity, $1 \mathrm{E}-2$ to $1 \mathrm{E} 3 \mathrm{~Hz}$.

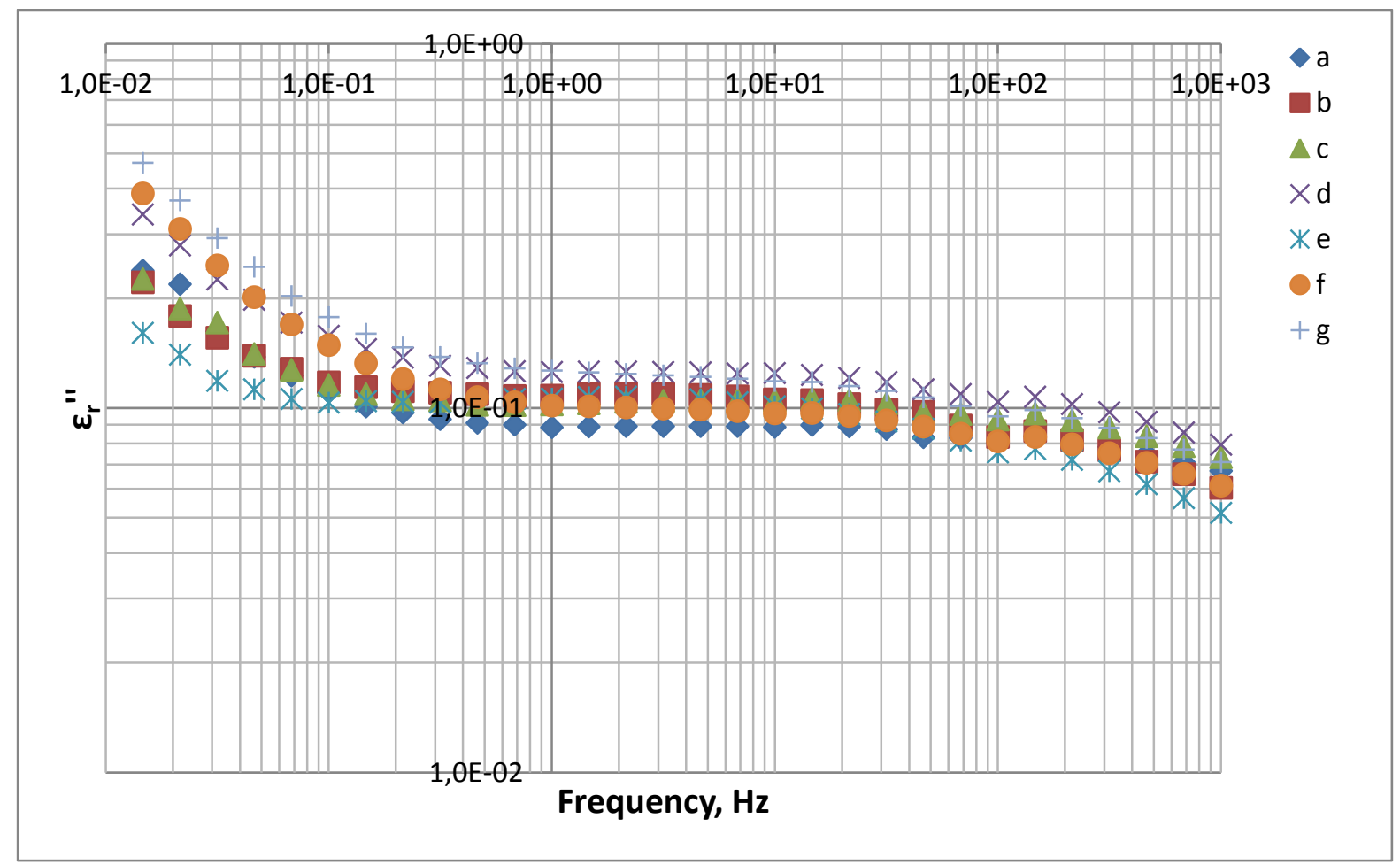

Figure 2 Imaginary Part of the Complex Relative Permittivity, 1E-2 to $1 \mathrm{E} 3 \mathrm{~Hz}$. 


\subsection{The tangent of dielectric loss angle}

The real relative permittivity and imaginary relative permittivity are both dependent upon accurate measurements of geometric thickness and contact area. Consider that the bitumen samples in this study were approximately $10 \mathrm{~mm}$ thick plus minus 0.5 $\mathrm{mm}$. Any thickness and/or area measurement errors would translate into errors in real relative permittivity and complex relative permittivity. In order to get way from geometric inaccuracies a material-related ratio was studied, i.e. loss tangent.

The frequency dependence of the tangent of the dielectric loss angle, loss tangent, of seven bitumen binders is illustrated in Figure 3. Loss tangent increases as the frequency is decreased. Above $1 \mathrm{~Hz}$, the differences in loss tangent among the samples $\boldsymbol{a}$ to $\boldsymbol{g}$ is small. Below $1 \mathrm{~Hz}$, the difference in loss tangent among the samples $\boldsymbol{a}$ to $\boldsymbol{g}$ increases and is significant.

According to the definition by Jonscher [3], low-loss dielectrics are materials with a loss tangent $<0.1$. Measurements in this study show that bitumen may be considered a low-loss material in the frequency range of $10^{-2}$ to $10^{0} \mathrm{~Hz}$ due to obtained $\tan \delta$-values $<0.1$. We should however keep in mind that $\tan \delta$ varies with frequency. It is therefore important to define frequency range for this statement. It is expected that the average of the tangent of the dielectric loss angle will be affected by the composition. This should be studied further.

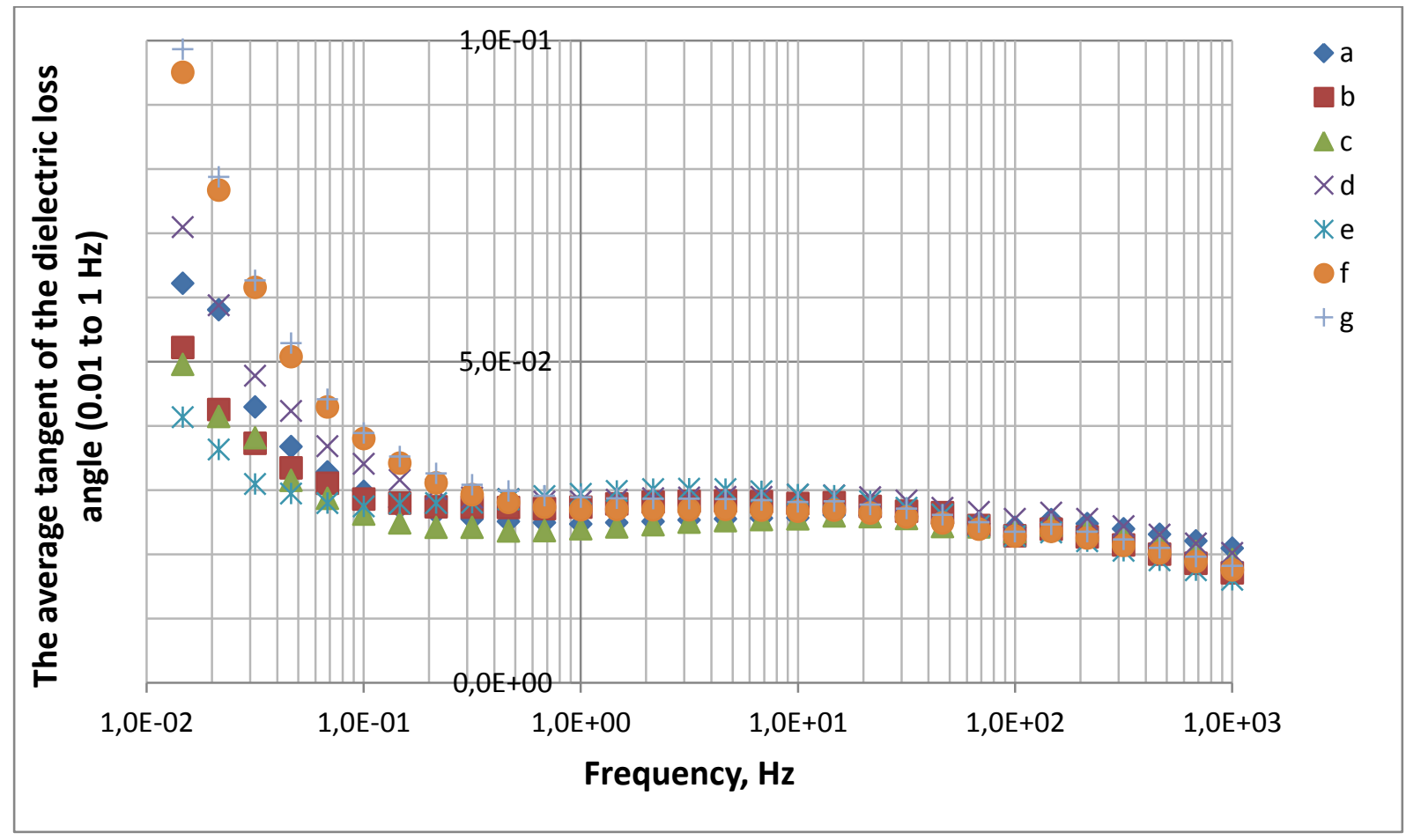

Figure 3 Tangent of Dielectric Loss Angle, 1E-2 to $1 \mathrm{E} 3 \mathrm{~Hz}$. 
The heptane insoluble fraction (i.e. asphaltenes) in the Athabasca bitumen has the highest conductivity of all the inherent fractions (i.e. heptane insoluble fraction > resins, maltenes) [4].

Permittivity and conductivity of a few bitumen binders were studied as a function of their concentration in toluene at $1 \mathrm{kHz}$ [5]. The results illustrate that conductivity is highly dependent upon the $n$-heptane insoluble fraction of bitumen. The relative impact on the dielectric constant is as follow: $n$-heptane insoluble fraction > resins > aromatics $>$ saturates.

The dielectric function response of four dissolved $n$-heptane insoluble fractions and one resin have been investigated as a function of the frequency-range $10^{-2}$ to $10^{\circ} \mathrm{Hz}$ [6] at different concentrations. The n-heptane insoluble fractions and resin were diluted in toluene. Vrålstad et al. [6] observed low frequency dispersion (LFD) according to [1], at low frequencies. At the same concentration the n-heptane insoluble fractions showed a significantly higher LFD than the resin fraction. Vrålstad et al. [6] attributed the 'LFD to the deposition of a capacitive layer of asphaltenes on the electrodes'.

There are two types of dielectric function responses at low frequencies: a) dipolar behavior and b) charge carrier behavior: 'dipolar polarization leaves zero residual polarization on discharging, while charge carrier give partial recovery on discharge but typically leave a limited polarization in the system' [see Fig 4 in] [7].

The bitumen binders in this paper follow the charge carrier type behavior as evidenced in that the curves have divergent character in the charge carrier system, as seen in Figures 2 and 3.

\subsection{Surface coverage by rolling bottle experiments}

In a recent study, surface coverage was investigated on the same bitumen binders by using the rolling bottle method where percentage bitumen adhering to quartz aggregates was determined after 24 hours agitation in water [31]. Surface coverage was measured at two different laboratories, Lab A and Lab B.

Without water in the system, the adhesion between quartz and bitumen is mostly from van der Waals type interactions. When water enters in between quartz and bitumen these interactions will be weakened.

Without any Portland cement added to the bitumen-aggregate mix, surface coverage was essentially non-existent (see Table 4). This is likely due to repulsive electrostatic 
forces formed when water comes between like-charged quartz and anionic polar groups on bitumen surfaces.

Portland cement was therefore added to the quartz aggregate surfaces to improve the surface coverage (i.e. adhesion) prior to bitumen being added to the mix. When Portland cement comes in contact with water it forms hydrated lime $\mathrm{Ca}(\mathrm{OH})_{2}$ that will chemically react with quartz surfaces. Ideally, cement is introduced as an intervening layer between the binder and the quartz aggregates (see Figure 4). This will provide the aggregates with positively charged surfaces that will attract anionic polar groups in bitumen and aid wetting and early bitumen to aggregate adhesion.

With the addition of the Portland cement, surface coverage increased but to a different extent for each binder. It was possible to obtain a good linear fit between the average tangent of the dielectric loss angle, (in the frequency range of $10^{-2}$ to $10^{0}$ $\mathrm{Hz}$ ) and the surface coverage using the rolling bottle method (coefficient of determination 0.89 for Lab A and 0.86 for Lab B), see Figure 5. The results show that the magnitude of the average tangent of the dielectric loss angle (average loss tangent) depends on bitumen type. Bitumen binders having a higher average loss tangent in the frequency region $10^{-2}$ to $10^{0} \mathrm{~Hz}$ display higher surface coverage on quartz aggregates when using Portland cement.

In order to obtain acceptable adhesion between 70/100 penetration grade bitumen binders and quartz aggregates when using Portland cement, it is suggested that:

- $\quad$ Portland cement may be used for binders where average $\tan \delta>0.035$

- $\quad$ It is suggested that an alternative adhesion promoter is used for binders where average $\tan \delta<0.035$

in the frequency range $10^{-2}$ to $10^{\circ} \mathrm{Hz}$.

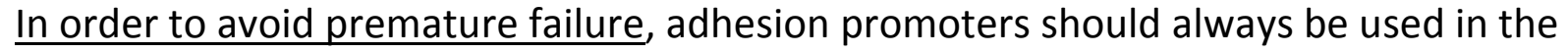
production of asphalt.

Table $4 \quad$ Surface Coverage and Average $\tan \delta(0.01$ to $1 \mathrm{~Hz})$.

\begin{tabular}{|l|l|l|l|l|}
\hline \multicolumn{2}{|l|}{ Laboratory A } & \multicolumn{2}{|l|}{ Laboratory B } & $\begin{array}{l}\text { Average tan } \boldsymbol{\delta} \\
(\mathbf{0 . 0 1} \text { to } \mathbf{1 ~ H z})\end{array}$ \\
\hline Reference & With cement & Reference & With cement & \\
\hline 0 & 10 & 0 & 10 & 0.0299 \\
\hline 0 & 20 & 0 & 10 & 0.0283 \\
\hline 0 & 63 & 0 & 53 & 0.0382 \\
\hline 0 & 25 & 0 & 22 & 0.0311 \\
\hline 0 & 38 & 0 & 30 & 0.0355 \\
\hline 0 & 15 & 0 & 0 & 0.0314 \\
\hline 5 & 65 & 0 & 62 & 0.0400 \\
\hline
\end{tabular}




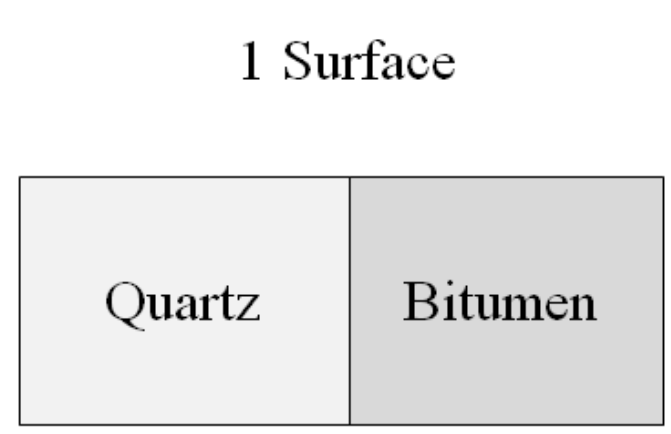

a.

\section{Surfaces}

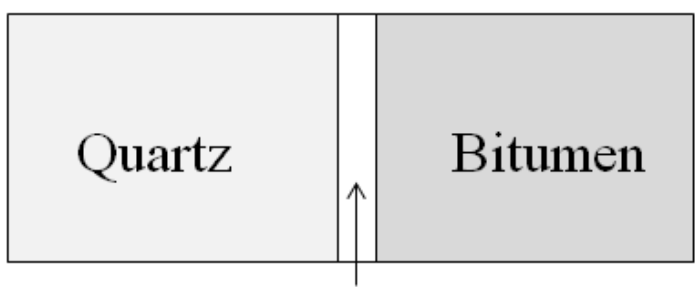

Cement

Figure 4 a. Quartz-Bitumen interaction, b. Quartz-Cement-Bitumen interaction.

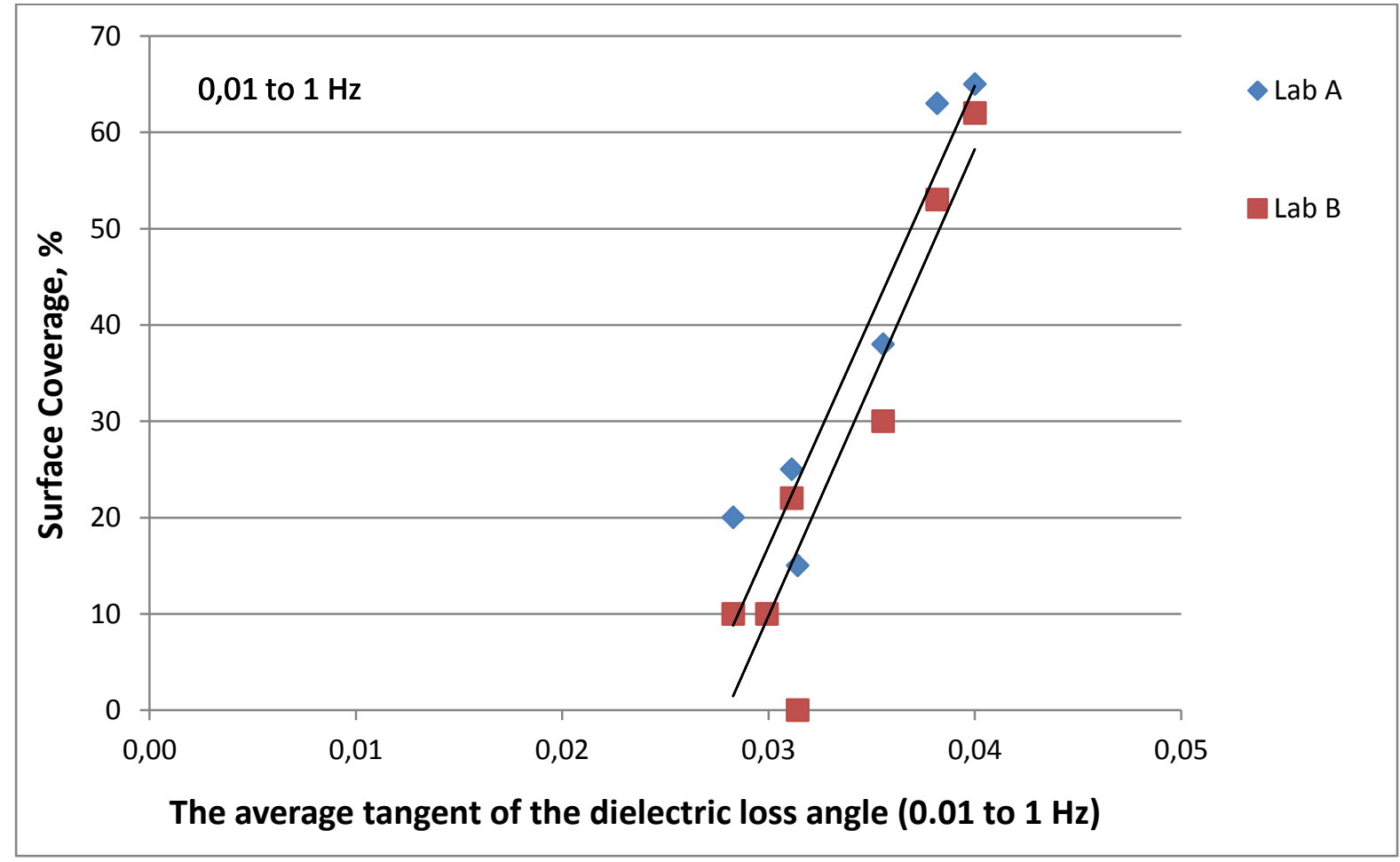

Figure 5 Surface coverage as a function of the average tangent of the dielectric loss angle. 


\section{CONCLUSIONS}

Attractive intermolecular forces bring the surfaces together in sufficiently close contact to promote wetting, orientation of molecules, and adhesion at elevated temperatures.

Surface coverage by the rolling bottle method (a common method to indicate suitability of bitumen for use in roads) could be seen as a measure of early adhesion. Without any Portland cement added to the bitumen-quartz mix, surface coverage was essentially non-existent. With the addition of the Portland cement, surface coverage increased but to a different extent for each binder.

A strong correlation was identified between the average tangent of the dielectric loss angle in the frequency region of $10^{-2}$ to $10^{\circ} \mathrm{Hz}$ and surface coverage. It is suggested that the average tangent of the dielectric loss angle in the frequency range $10^{-2}$ to $10^{0}$ $\mathrm{Hz}$, could be used as an indicator for predicting polarizability and thereby, adhesion potential of bitumen binders to quartz aggregates using Portland cement.

In order to avoid premature failure, adhesion promoters should always be used in the production of asphalt.

\section{ACKNOWLEDGEMENTS}

The work was supported by SBUF and by BVFF via Swedish Transport Administration. The authors thank Kenneth Olsson at Skanska and Mats Wendel at Peab for their support (earlier Swedish Transport Administration). The authors thank Thorsten Nordgren, Swedish Transport Administration, for supplying the bitumen samples. Måns Collin and Per Redelius are thanked for countless valuable discussions. 


\section{REFERENCES}

1. Linhjell, D., Lundgaard, L. and Gäfvert, U, Dielectric Response of Mineral Oil Impregnated Cellulose and the Impact of Aging. IEEE Transactions on Dielectrics and Electrical Insulation, 2007. 14(1): p. 156-168.

2. Jonscher, A.K., Universal Relaxation Law. Chelsea Dielectrics Press, London, UK, Chapter 5.4, 1996.

3. Jonscher, A.K., Relaxation in low-loss dielectrics. Journal of Molecular Liquids, 2000: p. 259268.

4. Penzes, S.a.S., J.G, Electrical conductivities of bitumen fractions in non-aqueous solvents. Fuel, 1974. 53: p. 192-197.

5. Chow, R.S., Tse, D.L., Takamura, K, The conductivity and dielectric behaviour of solutions of bitumen in toluene. Can. J. Chem. Eng, 2004. 82: p. 840-845.

6. Vrålstad, H., Spets, Ö., Lesaint, C., Lundgaard, L., Sjöblom, J, Dielectric properties of crude oil components. Energy Fuels, 2009. 23: p. 5596-5602.

7. Jonscher, A.K., Dielectric relaxation in solids. J. Phys. D: Appl. Phys, 1999. 32: p. R57-R70.

8. Wikipedia, http://www.wikipedia.org/wiki, 2014: p. Retrieved 2014-01-27.

9. Microcat, E., http://www.microcat.gr/msdspd90-99/Ethylbenzene.htm. , 2014. Retreived 2014-01-27.

10. King, C.J., Separation processes, 2013.

11. Kokosa, J.M., Przyjazny, A., Jeannot, M.A. , Solvent Microextraction Theory and Practice 2009.

12. Microcat, C., http://www.microkat.gr/msdspd90-99/Cyclohexylamine.htm, 2014. Retrieved 2014-01-27.

13. Rafoeg, http://www.rafoeg.de/20.../20, Daten/dielectric_chart.pdf, 2014. Retrieved 201401-27.

14. Macro, http://macro.Isu.edu/howto/solvents/THF.htm, 2014. Retrieved 2014-01-27.

15. Exvacuo, http://www.exvacuo.free.fr, 2014. 2014-01-27.

16. Microcat, C., http://www.microkat.gr/msdspd90-99/Cyclohexanone.htm, 2014. 2014-01-27.

17. Lanza, V.L.a.H., D.B. , The density of the dielectric constant of polyethylene. Journal of Polymer Science, 1958. 28(118): p. 622-625.

18. Anderson, E.W.a.M., D.W. , The dielectric constant and loss of polypropylene. Journal of Polymer Science, 1958. 31(122): p. 241-242.

19. Csgnetwork, http://www.csgnetwork.com/dieconstantstable.html, 2014. 2014-05-14.

20. Rabuffi, M.a.P., G. , Status quo and future prospects for metallized polypropylene energy storage capacitors IEEE Transactions on plasma science 2002. 30(5): p. 1939-1942.

21. Havriliak, S.a.N., S., A complex plane representation of dielectric and mechanical relaxation processes in some polymers. . In Polymers. Elsevier, 1967. 8: p. 161-210.

22. Maruska, H.P., and Rao, B.M.L, The role of polar species in aggregation of asphaltenes. Fuel Science and Technology International, 1987. 5(2): p. 119-168.

23. Goual, L., and Firoozabadi, A. , Measuring asphaltenes and resins, and dipole moment in petroleum fluids. AlChE Journal 2002. 48(11): p. 2646-2663.

24. Lyne, Å.L., Krivosheeva, O., and Birgisson, B. , Adhesion between bitumen and aggregate Implementation of spectroscopic ellipsometry characterisation and estimation of Hamaker's constant. Materials and Structures, 2013b. 46: p. 1737-1745.

25. Neville, A.M., and Brooks, J.J, Concrete Technology. Second Edition. 1987.

26. WebMineral, www.webmineral.com [Retreived 2014-03-12]. 2014.

27. WebMineral, Electronic. Available: Webmineral.com 2015-02-15. 2015.

28. Kim, Y.-H., Hwang, M.S., and Kim, H.J, Infrared spectroscopy study of low-dielectric-constant fluorine-incorporated and carbon-incorporated silicon oxide films. Journal of Applied Physics, 2001. 90(7): p. 3367-3370. 
29. Subramanian, M.A., Shannon, R.D., Chai, B.H.T., Abraham, M.M., and M.C. Wintergill, M.C, Dielectric constants of $\mathrm{BeO}, \mathrm{MgO}$, and $\mathrm{CaO}$ using the two-terminal method. Phys Chem Minerals, 1989. 16: p. 741-746.

30. Kück, S., Werheit, H. Madelung, O. (Ed.), Non-Tetrahedrally Bonded Binary Compounds II, Landolt-Börnstein - Group III Condensed Matter. 2000. 41D.

31. Olsson, K., Krona, N., and Nordgren, T, Asphalt concrete test sections containing bitumen of different origins. SBUF report 12091. 2010.

32. Barnes, G.T., and Gentle, I.R, Interfacial science: an introduction. Second edition. Oxford university press. 